\title{
ACTIVATED CARBON PRODUCED FROM SASOL-LURGI GASIFIER PITCH AND ITS APPLICATION AS ELECTRODES IN SUPERCAPACITORS
}

\author{
A. Alonso, V. Ruiz, C. Blanco*, R. Santamaría, M. Granda, R. Menéndez and S.G.E. de \\ Jager $^{\#}$ \\ Instituto Nacional del Carbon, CSIC, Apdo. 73, 33080-Oviedo, Spain \\ \#Sasol Technology (Pty) Ltd, R\&D Division, P.O. Box 1, Sasolburg-1947 (South Africa)
}

\begin{abstract}
A pyrolysis product derived from SASOL-Lurgi gasifier pitch was activated using different proportions of $\mathrm{KOH}$. The increase of the amount of $\mathrm{KOH}$ used for activation caused the activation degree of the carbons to increase very significantly. The activated carbons obtained using lower amounts of $\mathrm{KOH}$ were mainly microporous, while the amount of mesopores developed in the samples progressively increased for the carbons activated with higher proportions of $\mathrm{KOH}$. The gravimetric specific capacitance of samples obtained with $(2: 1),(3: 1)$ and $(5: 1) \mathrm{KOH}$ to carbon ratio were rather similar at low current densities ( $\sim 400 \mathrm{~F} / \mathrm{g}$ at low current densities), despite the significant differences observed in their textural characteristics. Supercapacitors built with the activated carbons obtained with $(2: 1)$ and $(3: 1) \mathrm{KOH}$ to carbon ratio yielded the highest volumetric capacitance (higher than $200 \mathrm{~F} / \mathrm{cm}^{3}$ at low current densities), while the most activated sample yielded the lowest values, due to the significant reduction in density caused by activation. The high values of capacitance observed result from the combination of two mechanisms of energy storage: double layer formation and pseudocapacitance.
\end{abstract}

Keywords- A. Pitch, Coke; B. Activation; D. Adsorption properties, Electrochemical properties

\footnotetext{
* corresponding author: clara@incar.csic.es; Fax.: +34 985297662
} 


\section{Introduction}

Supercapacitors have been presented in the last years as an important alternative or complement to other energy storage or generation devices such as secondary batteries and fuel cells [1]. Carbon materials have been shown as the most attractive electrode materials for these supercapacitors, as a consequence of their relatively low cost, high surface area and availability [2]. Despite the intensive research in this field, there is still a strong need for understanding the role played by the porosity and the interactions between the porous carbon and the liquid electrolyte. Most of the studies that have been published tend to explain the electrochemical behaviour based mainly on the textural characteristics (surface area, pore size, etc.) of activated carbons, although it is evident for the scientists involved in this field that many other factors play a key role. Important aspects to be taken into account are, for example, the surface chemistry (influenced by the $\mathrm{pH}$ of the media) and the electronic structure of the activated carbon. Additionally, the size of the solvated ions and the changes in their coordination sphere that may occur when the double layer is formed need also to be considered.

The situation is even more complex due to the large variety of carbon precursors. The classical activated carbons are based on lignocellulosic or coal-derived materials [3], which are characterised by a low crystalline order, while other high surface carbon materials can be derived from such diverse materials as nanotubes [4] or graphitic carbon fibres [5], which present a much higher crystalline order. In addition to the different nature of the precursors, the activation procedures used to develop surface area in each case may be different (i.e. physical or chemical activation) [3-7], which can still generate further differences in the characteristics of the surface. 
In this paper, a highly functionalised pitch supplied by SASOL was used as raw material. A semicoke obtained from this pitch was chemically activated using different proportions of $\mathrm{KOH}$ to produce porous carbons that were then used as electrodes in supercapacitors. The influence that the activation conditions have on the type of porosity developed in the semicoke and the relationships between this porosity and the specific capacitance of the materials are investigated.

\section{Experimental}

\subsection{Preparation of the semicoke.}

Sasol-Lurgi Gassifier pitch was pyrolised at $450^{\circ} \mathrm{C}$ for 4 hours under a dynamic nitrogen pressure of $1 \mathrm{MPa}$ and a flow of $40 \mathrm{~L} \mathrm{~h}^{-1}$. The resultant sample, which was $97 \%$ anisotropic, was labelled SP-4 and was used as raw material for the chemical activation.

\subsection{Preparation of activated carbons.}

Sample SP-4 was chemically activated using different proportions of $\mathrm{KOH}(1: 1,2: 1,3: 1$ and 5:1 $\mathrm{KOH}$ to carbon ratio). The semicoke and the $\mathrm{KOH}$ were mixed in an agate ball mill and then treated at $700^{\circ} \mathrm{C}$ for one hour, under a nitrogen flow of $62 \mathrm{~mL} \mathrm{~min}{ }^{-1}$. The resultant material was neutralized with $1 \mathrm{M} \mathrm{HCl}$ and then washed with distilled water until $\mathrm{pH}=7$. Finally, the carbon was dried at $110^{\circ} \mathrm{C}$ in a vacuum oven for $24 \mathrm{~h}$. The resultant activated carbons were labelled SP4-1, SP4-2, SP4-3 and SP4-5, respectively, where the ratio of $\mathrm{KOH}$ used is indicated. 


\subsection{Characterisation of activated carbons.}

The resultant activated carbons were characterized by elemental analysis, with direct determination of oxygen, using a LECO-TF-900 furnace coupled to a LECO-CHNS-932 microanalyser.

Physical adsorption of $\mathrm{N}_{2}$ at $77 \mathrm{~K}$ was carried out in order to characterise the porous structure of the activated carbons. The apparent surface area was determined by BET equation from the $\mathrm{N}_{2}$ adsorption isotherm. The total micropore volume was calculated from the application of the Dubinin-Radushkevich (DR) equation to the isotherm. The total pore volume was obtained from the $\mathrm{N}_{2}$ adsorption at $\mathrm{P} / \mathrm{P}_{0}=0.99$. The volume of mesopores was calculated by subtracting the total micropore volume from the total pore volume. The pore size distribution in the different activated carbons was estimated by DFT, assuming slit shape pores.

The microporosity of the activated carbons was further characterised by measuring the enthalpy of immersion of the samples into liquids of different critical dimensions [8]. Measurements were carried out at $20^{\circ} \mathrm{C}$ using dichloromethane $\left(\mathrm{CH}_{2} \mathrm{Cl}_{2}, \mathrm{~L}=0.33 \mathrm{~nm}\right)$, benzence $\left(\mathrm{C}_{6} \mathrm{H}_{6}, \mathrm{~L}=0.41 \mathrm{~nm}\right)$, cyclohexane $\left(\mathrm{C}_{6} \mathrm{H}_{12}\right)$, carbon tetrachloride $\left(\mathrm{CCl}_{4}, \mathrm{~L}=0.63\right.$ $\mathrm{nm})$ and tri-2,4-xylylphosphate (TXP, $\mathrm{L}=1.5 \mathrm{~nm})$.

The $\mathrm{pH}$ of the activated carbons was determined according to the ASTM D3838-80. The samples were boiled in reagent water using a reflux condenser for $900 \mathrm{~s}$. Then the carbon particles were filtered out and the $\mathrm{pH}$ of the filtrate measured after cooling down. 
The real density of the activated carbons was determined using an AccuPyc helium picnometer. The apparent density of the powders was also estimated using an adaptation of ASTM D2854-96.

The electrical conductivity of the activated carbons was determined using a four-point probe method. The measurements were performed at various pressures that were assessed using a load cell for better accuracy.

\subsection{Electrochemical characterisation of activated carbons.}

The electrochemical performance of the activated carbons in supercapacitors was studied from galvanostatic charge-discharge cycles of a two electrode Swagelok type cell using an aqueous solution of sulphuric acid (2 M) as electrolyte. Coin type carbon electrodes (12 $\mathrm{mm}$ in diameter and about $500 \mu \mathrm{m}$ in thickness) were prepared by mixing $90 \mathrm{wt} . \%$ of the activated carbon with 10 wt. \% of PVDF as binder. The bulk density of the electrodes was calculated by from the dimensions of the pellets.

The capacitor was constructed using two of these electrodes, separated by a disc of glassy paper. Galvanostatic charge-discharge characteristics were measured in the range of $0-1$ $\mathrm{V}$ at various current intensities (1-100 mA). The gravimetric specific capacitance was calculated from the linear region $(\sim 0.2-0.6 \mathrm{~V})$ of the discharge branch, taking into account the mass of activated carbon used in the lightest electrode. The volumetric specific capacitance was also calculated from the same tests but using the volume of the electrodes. This volume was directly calculated from the thickness (measured with a laser device) and diameter of the pellets. Cyclic voltametry was also performed on sample 
SP4-3 in order to evidence the presence of pseudocapacitance. The tests were performed in an Autolab M30 at a scan rate of $1 \mathrm{mV} / \mathrm{s}$ and a voltage range of 0 to $1 \mathrm{~V}$.

\section{Results and Discussion}

\subsection{Characteristics of activated carbons}

The activation yields obtained for the different proportions of $\mathrm{KOH}$ used are summarised in Table 1. As could be expected, the yield significantly decreased (from 80 to $46 \mathrm{wt}$ \%) with increasing the amount of activating agent. This is reflected in the capacity of the samples to adsorb nitrogen, as observed in the nitrogen isotherms (Figure 1 a) and the volume of pores developed (Table 1), which varied from 0.41 to $1.57 \mathrm{~cm}^{3} / \mathrm{g}$ for samples SP4-1 and SP4-5, respectively. The shape of the isotherms corresponding to samples SP4-1, SP4-2 and SP4-3 indicates that these are mainly microporous samples, while the most activated sample, SP4-5, shows an isotherm with a relatively broad knee (Figure 1 b), indicative of the presence of pores of larger size. In fact, the volume of mesopores estimated for this sample is $0.55 \mathrm{~cm}^{3} / \mathrm{g}$, rather significant as compared to the rest of the samples studied. The volume of micropores is also higher in this sample, which suggest that the increase of the amount of activating agent promotes the development of new micropores and the widening of the already developed ones. The BET surface area also increases with increasing the amount of $\mathrm{KOH}$ used during activation, varying from 904 to $3204 \mathrm{~m}^{2} / \mathrm{g}$ for samples SP4-1 and SP4-5, respectively. The results obtained follow the same trend as those found by other authors [5].

The activated carbons were also characterised by liquid immersion calorimetry using liquids of different size. The results are summarised in Table 2. The increase of the amount of activating agent caused the immersion enthalpy in the liquid of the smallest 
size $\left(\mathrm{CH}_{2} \mathrm{Cl}_{2}\right)$ to increase from 140 to $281 \mathrm{~J} / \mathrm{g}$, which is in agreement with the higher surface developed in the carbons, as discussed from the isotherm data. A similar trend was observed for the rest of the liquids used. The immersion enthalpy in TXP of the least activated sample (SP4-1) is significantly lower than that obtained for the other liquids, indicating that the TXP molecule is not accessible to the pores developed in this sample, i.e. they are smaller than $1.5 \mathrm{~nm}$. In the case of the sample SP4-2, the enthalpy of immersion in TXP is also lower than for the rest of the liquids, although the differences are not as significant as in the previous sample. This indicates that only a small proportion of the pores present in this sample are larger than $1.5 \mathrm{~nm}$. On the other hand, the samples activated with a higher proportion of $\mathrm{KOH}, \mathrm{SP} 4-3$ and SP4-5, have very high values of immersion enthalpy into TXP (comparable to those obtained into the liquid of smallest size), especially in sample SP4-5, which indicates that most of the pores present in these samples are larger than $1.5 \mathrm{~nm}$.

The pore size distribution of the activated carbons obtained by DFT (Figure 2) corroborates the results discussed above, indicating that the increase of the amount of $\mathrm{KOH}$ used for activation promotes the development of pores of larger size. Most of the porosity developed in SP4-1 is lower than $1 \mathrm{~nm}$, while the size progressively increases with increasing the activation degree, reaching the range of mesopores. In fact, sample SP4-5 contains a significant proportion of pores larger than $2 \mathrm{~nm}$ (between 2 and $3 \mathrm{~nm}$ ).

As a result of the activation with $\mathrm{KOH}$, oxygenated functional groups were introduced in the semicoke, as the oxygen content increased from 1.89 wt. \% to higher than 4 wt. \%, respectively. The oxygen content in the activated carbons decreased with increasing the degree of activation (Table 3), which is due to a higher release of $\mathrm{CO}$ and/or $\mathrm{CO}_{2}$ in the 
most activated samples. As could be expected, the $\mathrm{pH}$ of the carbons increased as the oxygen content decreased, probably due to a smaller contribution of carboxylic acids to the surface chemistry of the samples.

The real density of the activated carbons (Table 4) increased with increasing the activation degree, which is associated with the delamination of the graphene layers caused by the potassium intercalation [9]. These values are close to the density of graphite $\left(2.25 \mathrm{~g} / \mathrm{cm}^{3}\right)$ or even higher, which could be related to helium adsorption, a phenomenon previously described in the literature [10]. On the other hand, the apparent density decreased with increasing the activation degree of the samples, as could be expected. The bulk density of the electrodes followed the same trend observed for the apparent density of the powders. It is worth noting that the density of the electrode made from the most activated sample (SP4-5) is $0.39 \mathrm{~g} / \mathrm{cm}^{3}$, which is almost half of that of the least activated sample SP4-1.

The electrical conductivity of the samples is a very important property for their electrochemical performance, as it contributes to reduce the ESR of the supercapacitor and, therefore, increases the power of the device. The conductivity of the activated carbons (Figure 3) decreased with increasing the activation degree, the values obtained for sample SP4-1 being significantly higher than those corresponding to the rest of the samples. This could be related to the higher packing ability of this sample (as reflected by its higher apparent density), but also to its less distorted crystalline structure, as corroborated by X-ray diffraction.

\subsection{Electrochemical performance of activated carbons}


The electrochemical behaviour of the samples was studied from the galvanostatic chargedischarge cycles. The results are summarised in Figure 4. As could be expected, the least activated sample (SP4-1) has the lowest gravimetric specific capacitance values in the whole range of current density (varying between 275 and $160 \mathrm{~F} / \mathrm{g}$ ). The gravimetric specific capacitances of the rest of the samples are significantly higher, with values around $400 \mathrm{~F} / \mathrm{g}$ at low current densities. At high current densities sample SP4-3 has the highest capacitance values (300 F/g), while SP4-2 and SP4-5 show very similar values ( $250 \mathrm{~F} / \mathrm{g}$ ). It is worth noting the similar electrochemical behaviour observed for these two samples, despite the significant differences in their textural characteristics. One would expect sample SP4-5 to have the highest gravimetric specific capacitance due to its significantly higher surface area accompanied by the larger size of the porosity developed in this sample. These results clearly indicate that although the surface area or pore volume developed in the carbons is important in order to obtain high capacitance values, there are other factors playing an important role in the electrochemical behaviour. A possible explanation for the results obtained for sample SP4-5 could be related with the significantly lower electrical conductivity of this sample (Figure 2), which would hinder the electron transportation within the sample, which is necessary for the formation of the electric double layer. Barbieri et al. [11] have also found that the gravimetric capacitance does not increase linearly with specific surface area, but exhibits a plateau for large surface areas. These authors suggest that the capacitance limitation observed could be ascribed to a space constriction for charge accommodation inside pore walls, as for large surface area values, the pore wall can no longer accommodate the same amount of charge at a given electrode potential. 
Another factor that may be playing an important role in the electrochemical behaviour of these carbons is pseudocapacitance, resultant from their high content in oxygenated functional groups. Evidences of pseudocapacitance are found in the voltagram obtained for sample SP-3 (Figure 5). However, it is difficult to assign the amount of capacitance resultant from the double layer formation and that resultant from pseudocapacitance. It is generally accepted that pseudocapacitance can contribute to the total capacitance up to around $10 \%$. However, in this type of samples the contribution could be much higher.

The volumetric specific capacitance (Figure 4 b) was also estimated using the bulk density of the electrodes. These values are significantly lower than the corresponding gravimetric ones. As could be expected, the volumetric specific capacitance of the sample with the highest degree of activation (SP4-5) is now significantly lower, presenting the lowest capacitance. Samples SP4-2 and SP4-3 showed the highest volumetric capacitance (values varying between $\sim 200$ and $150 \mathrm{~F} / \mathrm{cc}$ for low and high current densities, respectively), as a result of the combination of high specific capacitance and high density.

\section{Conclusions}

The increase of the $\mathrm{KOH}$ to carbon ratio caused the volume of pores to increase very significantly, accompanied by the increase of the pore size. Activation with low $\mathrm{KOH}$ ratios promoted the development of mainly microporous carbons, whereas a significant proportion of mesopores were developed when $(5: 1) \mathrm{KOH}$ to carbon ratio was used. Activation also caused a significant increase of the oxygen content of the samples. 
The gravimetric specific capacitance of the activated carbons increased with increasing the activation degree, except for the most activated sample, despite its significantly higher surface area and pore size. This different trend could be due to the decrease in electrical conductivity or the reduced ability to accommodate charge inside the pore walls of this sample.

Another factor contributing to the high capacitance values observed, which has been evidenced but is difficult to quantify, is pseudocapacitance, resultant from the high content in oxygenated functionalities present in the activated carbons.

$\mathrm{KOH}$ to carbon ratio can be optimised to maximize both the gravimetric and volumetric capacitance. Gravimetric capacitance as high as $400 \mathrm{~F} / \mathrm{g}$ and volumetric capacitance over 200 F/cc were obtained for samples SP4-2 and SP4-3.

Acknowledgements.- The authors would like to thank SASOL and Spanish Education Ministry (project MAT-2004-03480-C02) for financial support and Teresa A. Centeno for the help with the immersion calorimetry tests. V. Ruiz thanks FICYT for a research grant.

\section{References}

[1] Kötz R, Carlen M. Principles and applications of electrochemical capacitors. Electrochimica Acta 2000; 45: 2483-2498. 
[2] Frackowiak E, Béguin F. Carbon materials for the electrochemical storage of energy in capacitors. Carbon 2001; 39: 937-950.

[3] Lozano-Castelló D, Cazorla-Amorós D, Linares-Solano A, Shiraishi S, Kurihara H, Oya A. Influence of pore structure and surface chemistry on electric double layer capacitance in non-aqueous electrolyte. Carbon 2003; 41: 1765-1775.

[4] Frackowiak E, Jurewicz K, Delpeux S, Beguin F. Nanotubular materials for supercapacitors. Journal of Power Sources 2001; 97-98: 822-825.

[5] Kim YJ, Horie Y, Matsuzawa Y, Ozaki S, Endo M, Dresselhaus M. Structural features necessary to obtain a high specific capacitance in electric double layer capacitors. Carbon 2004; 42: 2423-2432.

[6] Babel K, Jurewicz K. Electrical capacitance of fibrous carbon composites in supercapacitors. Fuel Processing technology 2002; 77-78: 181-189.

[7] Mitani S, Lee SI, Yoon SH, Korai Y, Mochida I. Activation of raw pitch coke with alkali hydroxide to prepare high preformance carbon for electric double layer capacitor. Journal of Power Sources 2004; 133: 298-301.

[8] Stoeckli F, Centeno TA. On the characterisation of microporous carbons by immersion calorimetry alone. Carbon 1997; 8: 1097-1100.

[9] Lillo-Ródenas MA, Cazorla-Amorós D, Linares-Solano A. Understanding chemical reactions between carbons and $\mathrm{NaOH}$ and $\mathrm{KOH}$ : An insight into the chemical activation mechanism. Carbon 2003; 41: 267-275.

[10] Kini KA, Stacy WO. The adsorption of helium by carbonaceous solids. Carbon 1963; 1: $17-24$.

[11]Barbieri O, Hahn M, Herzog A, Kötz R. Capacitance limits of high surface area activated carbons for double layer capacitors. Carbon 2005; 43: 1303-1310. 


\section{Table Captions}

Table 1.- Properties of activated carbons.

Table 2.- Results obtained by immersion calorimetry.

Table 3.- Oxygen content and $\mathrm{pH}$ of the activated carbons.

Table 4.- Density of the samples. 
Table 1. Properties of activated carbons.

\begin{tabular}{lcccccc}
\hline Sample & AY & $\mathrm{V}_{\mathrm{T}}$ & $\mathrm{V}_{\text {micro }}$ & $\mathrm{V}_{\text {meso }}$ & $\mathrm{L}_{\mathrm{o}}$ & $\mathrm{S}_{\mathrm{BET}}$ \\
\hline $\mathrm{SP} 4-1$ & 80.4 & 0.41 & 0.41 & 0.00 & 0.57 & 904 \\
$\mathrm{SP} 4-2$ & 70.5 & 0.74 & 0.72 & 0.02 & 0.84 & 1611 \\
$\mathrm{SP} 4-3$ & 58.2 & 1.03 & 0.85 & 0.18 & 1.2 & 2335 \\
$\mathrm{SP} 4-5$ & 46.3 & 1.57 & 1.02 & 0.55 & 1.7 & 3204 \\
\hline AY, activation yield $(\mathrm{wt.} \%)$ & \multicolumn{2}{l}{$\mathrm{V}_{\text {meso }}$, mesopore volume $\left(\mathrm{cm}^{3} / \mathrm{g}\right)$} \\
$\mathrm{V}_{\mathrm{T}}$, total pore volume $\left(\mathrm{cm}^{3} / \mathrm{g}\right)$ & \multicolumn{2}{l}{$\mathrm{L}_{\mathrm{o}}$, average pore diameter $(\mathrm{nm})$} \\
$\mathrm{V}_{\text {micro }}$, micropore volume $\left(\mathrm{cm}^{3} / \mathrm{g}\right)$ & \multicolumn{2}{l}{$\mathrm{S}_{\text {BET }}$, BET surface area $\left(\mathrm{m}^{2} / \mathrm{g}\right)$}
\end{tabular}


Table 2. Results obtained by immersion calorimetry.

\begin{tabular}{cccccc}
\hline Sample & $-\Delta \mathrm{H}_{\mathrm{CH} 2 \mathrm{Cl} 2}$ & $-\Delta \mathrm{H}_{\mathrm{C} 6 \mathrm{H} 6}$ & $-\Delta \mathrm{H}_{\mathrm{C} 6 \mathrm{H} 12}$ & $-\Delta \mathrm{H}_{\mathrm{CC} 14}$ & $-\Delta \mathrm{H}_{\mathrm{TXP}}$ \\
\hline SP4-1 & 140 & 177 & 109 & 120 & 8 \\
SP4-2 & 228 & 233 & 187 & 193 & 130 \\
SP4-3 & 265 & 275 & 217 & 255 & 252 \\
SP4-5 & 281 & 293 & 245 & 277 & 305 \\
\hline
\end{tabular}
$\Delta \mathrm{H}$, Immersion enthalpies in the
$\mathrm{CH}_{2} \mathrm{Cl}_{2}$, molecular size $0.33 \mathrm{~nm}$
$\mathrm{C}_{6} \mathrm{H}_{6}$, molecular size $0.41 \mathrm{~nm}$
$\mathrm{C}_{6} \mathrm{H}_{12}$, molecular size $0.54 \mathrm{~nm}$
$\mathrm{CCl}_{4}$, molecular size $0.63 \mathrm{~nm}$
TXP, molecular size $1.5 \mathrm{~nm}$ 
Table 3. Oxygen content and $\mathrm{pH}$ of the activated carbons.

\begin{tabular}{lcl}
\hline Sample & O (wt. \%) & $\mathrm{pH}$ \\
\hline SP4-1 & 4.79 & 3.14 \\
SP4-2 & 4.64 & 3.45 \\
SP4-3 & 4.41 & 3.60 \\
SP4-5 & 4.12 & 3.76 \\
\hline
\end{tabular}


Table 4. Density of the samples.

\begin{tabular}{cccc}
\hline Sample & Real $\left(\mathrm{g} / \mathrm{cm}^{3}\right)$ & Apparent $\left(\mathrm{g} / \mathrm{cm}^{3}\right)$ & Bulk $\left(\mathrm{g} / \mathrm{cm}^{3}\right)$ \\
\hline SP4-1 & 2.035 & 0.53 & 0.69 \\
SP4-2 & 2.187 & 0.27 & 0.57 \\
SP4-3 & 2.232 & 0.21 & 0.49 \\
SP4-5 & 2.339 & 0.18 & 0.39 \\
\hline
\end{tabular}

Real: helium density of powder Apparent: apparent density of powder Bulk: bulk density of pellets (electrodes) 


\section{Figure Captions}

Figure 1.- a) $\mathrm{N}_{2}$ adsorption isotherms and b) normalized isotherms of samples activated with different $\mathrm{KOH}$ to carbon ratio.

Figure 2.- Pore size distribution of activated carbons estimated by DFT.

Figure 3.- Variation of the electrical conductivity of activated carbons with load.

Figure 4.- Variation of the capacitance with current density: a) gravimetric capacitance; b) volumetric capacitance.

Figure 5.- Voltagram of sample SP4-3 obtained at $1 \mathrm{mV} / \mathrm{s}$. 
a)

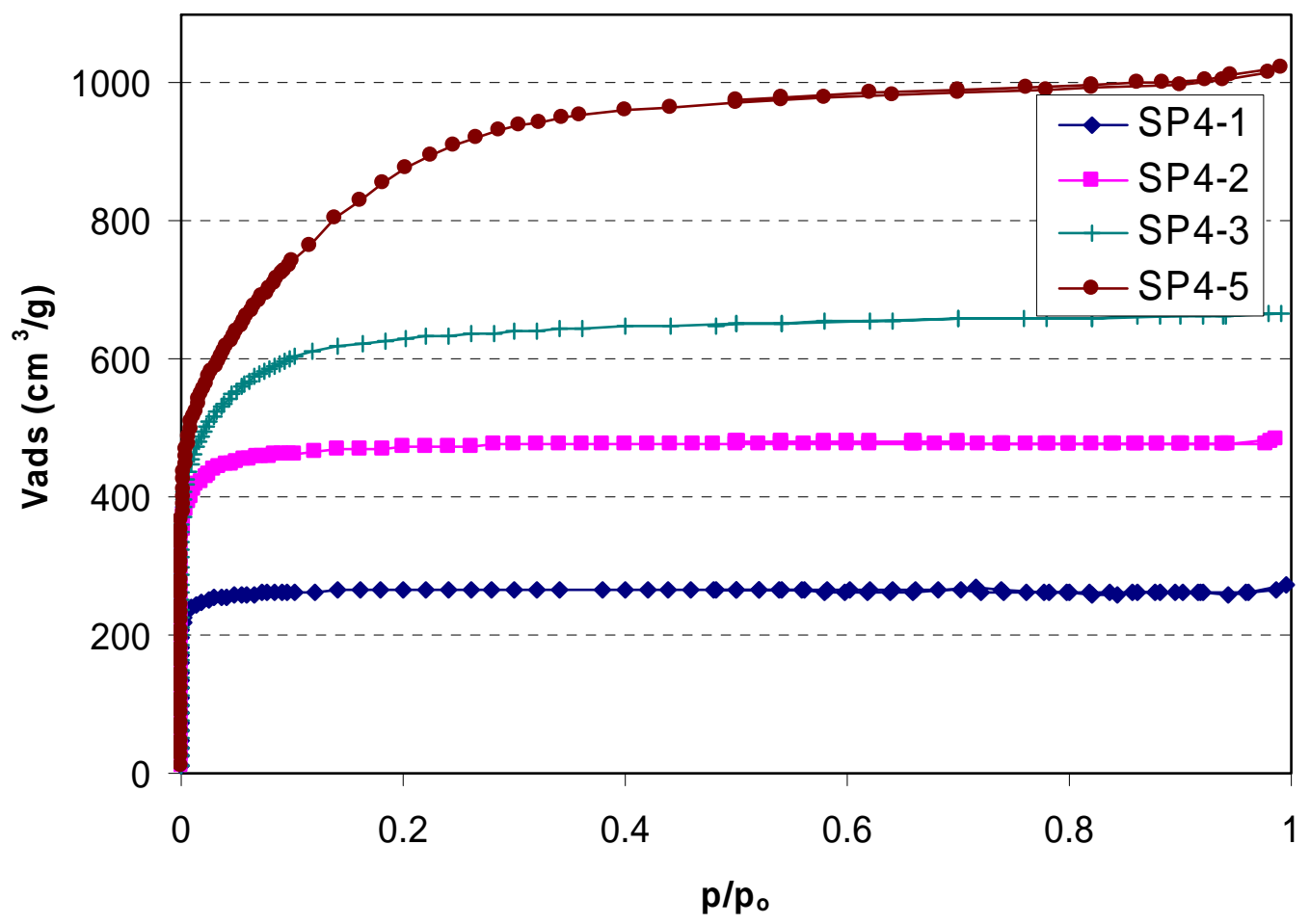

b)

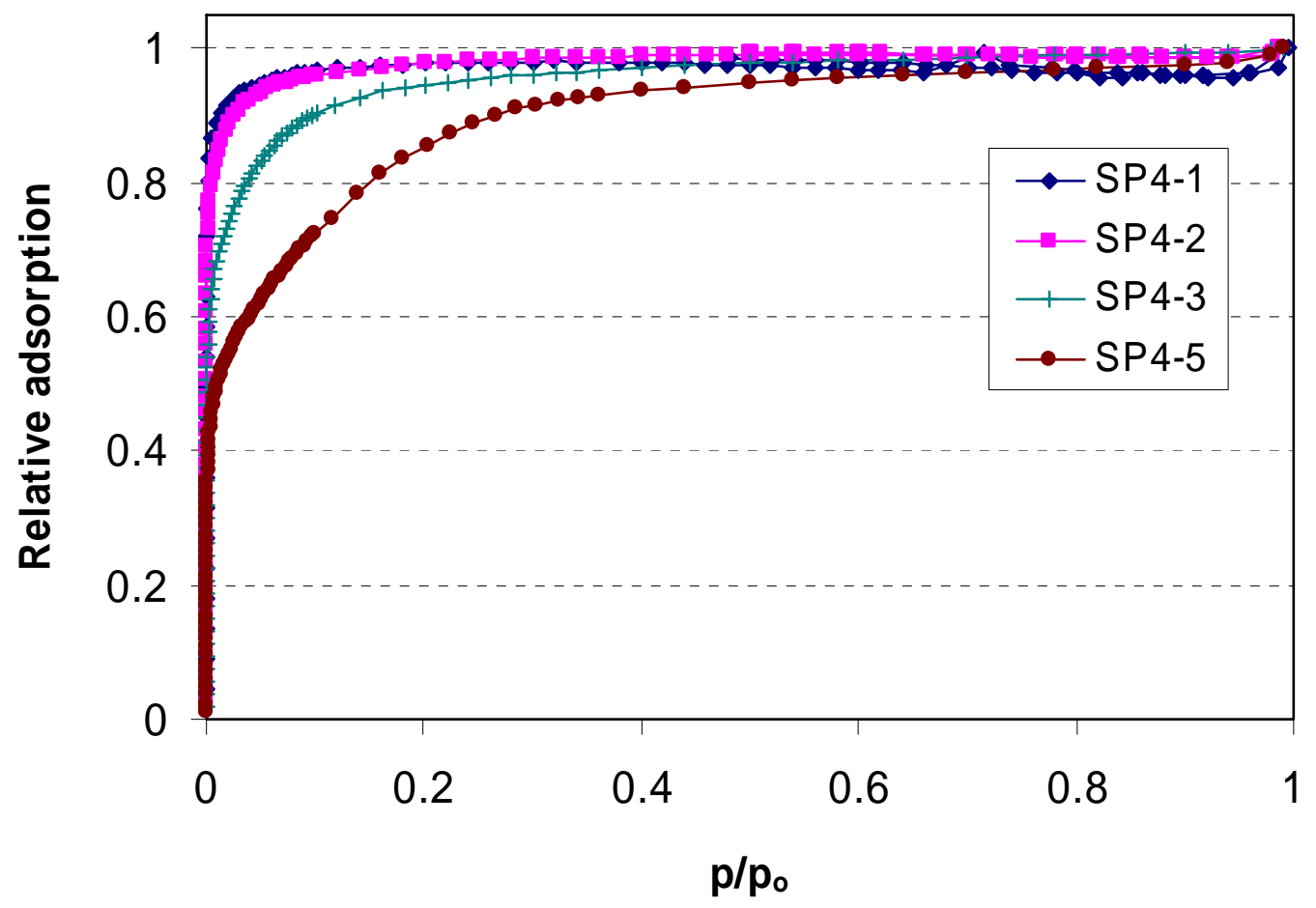

Figure 1.- a) $\mathrm{N}_{2}$ adsorption isotherms and b) normalized isotherms of samples activated with different $\mathrm{KOH}$ to carbon ratio. 


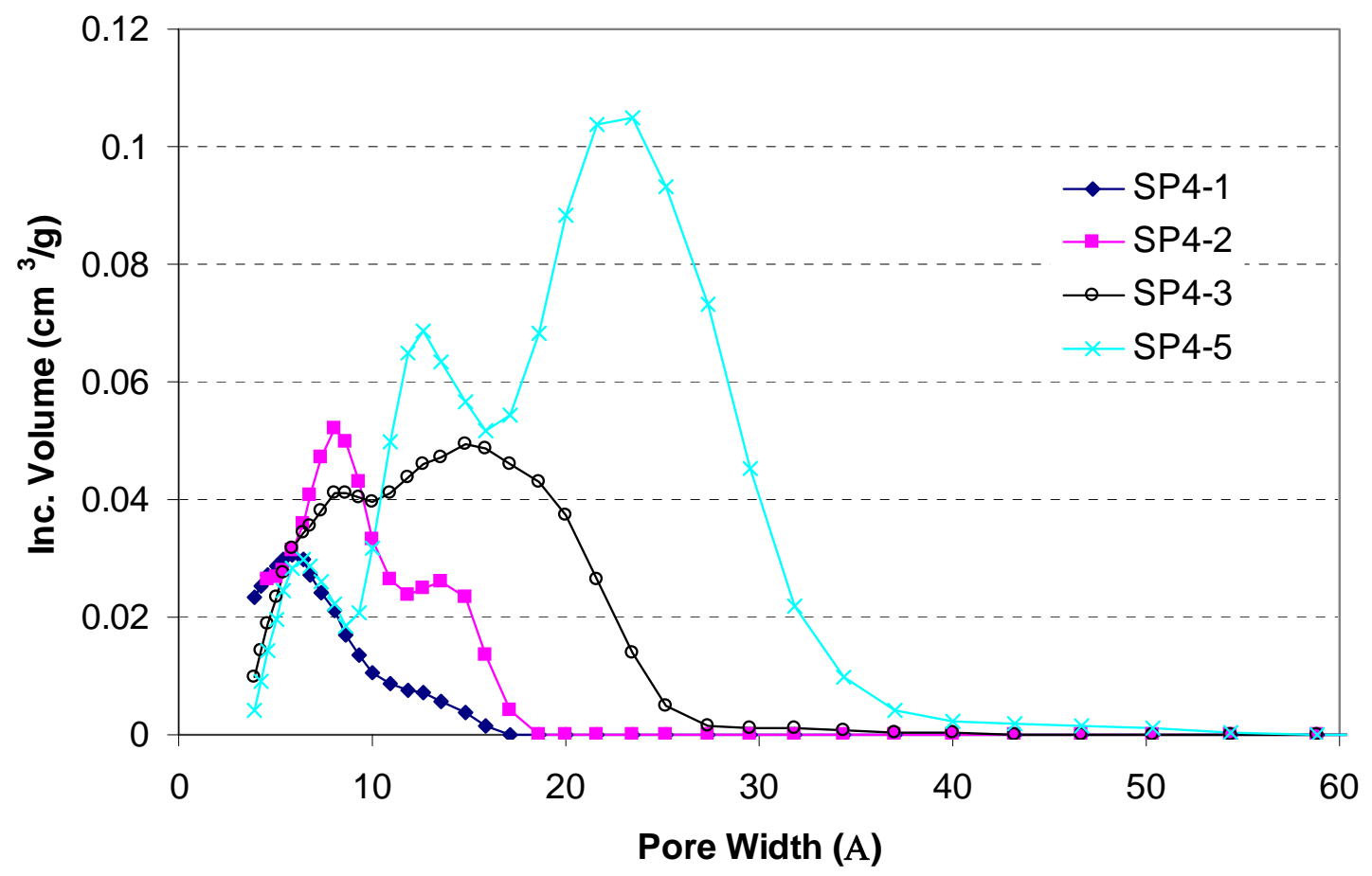

Figure 2.- Pore size distribution of activated carbons estimated by DFT. 


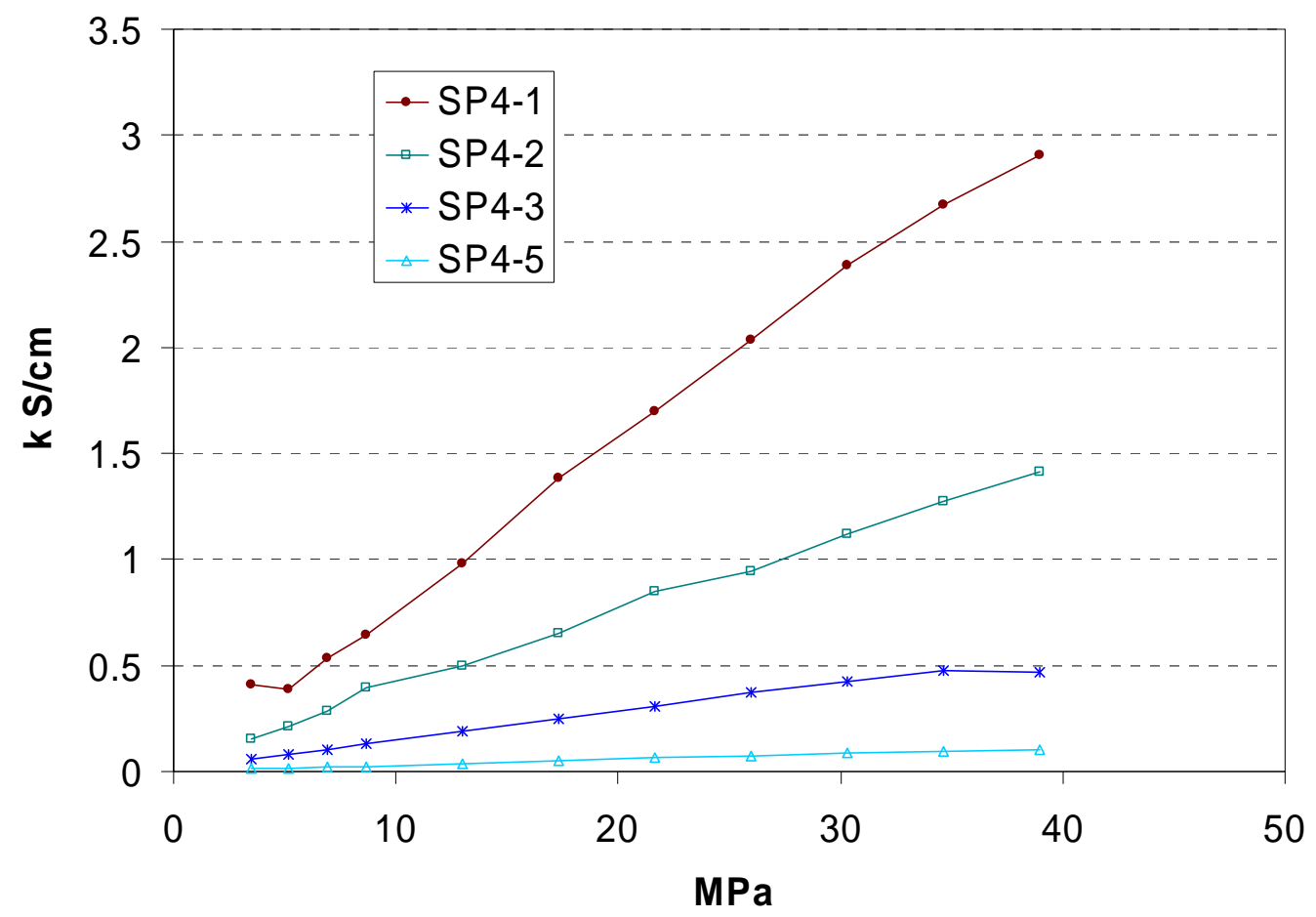

Figure 3.- Variation of the electrical conductivity of activated carbons with load. 
a)

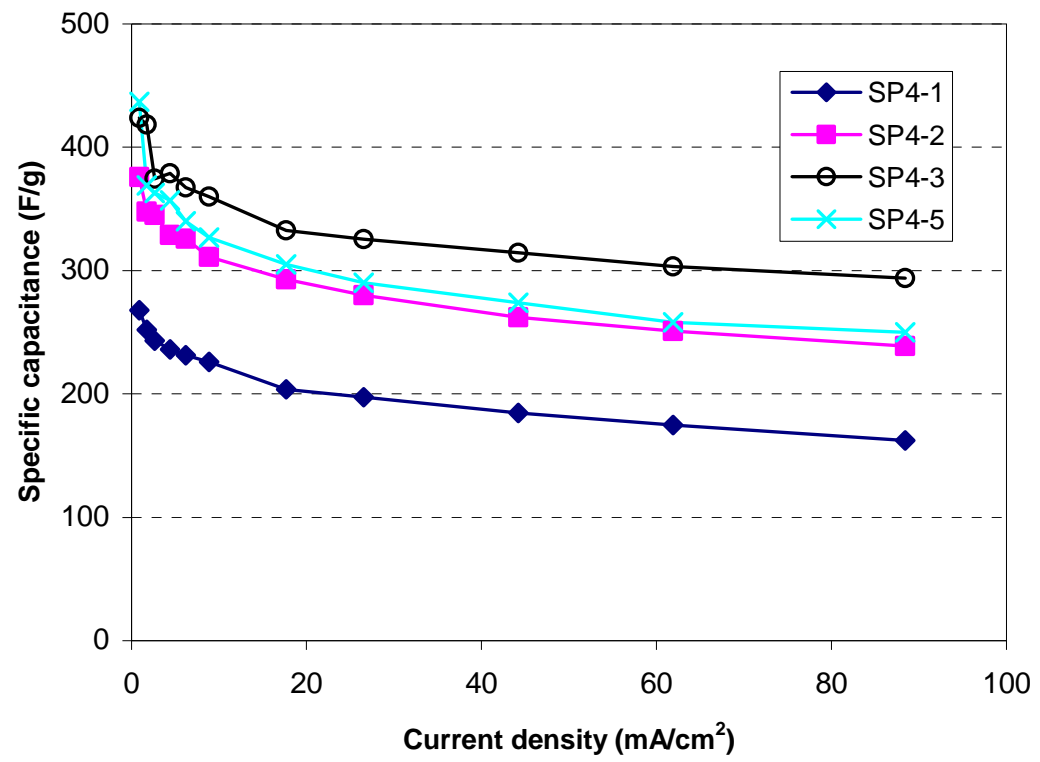

b)

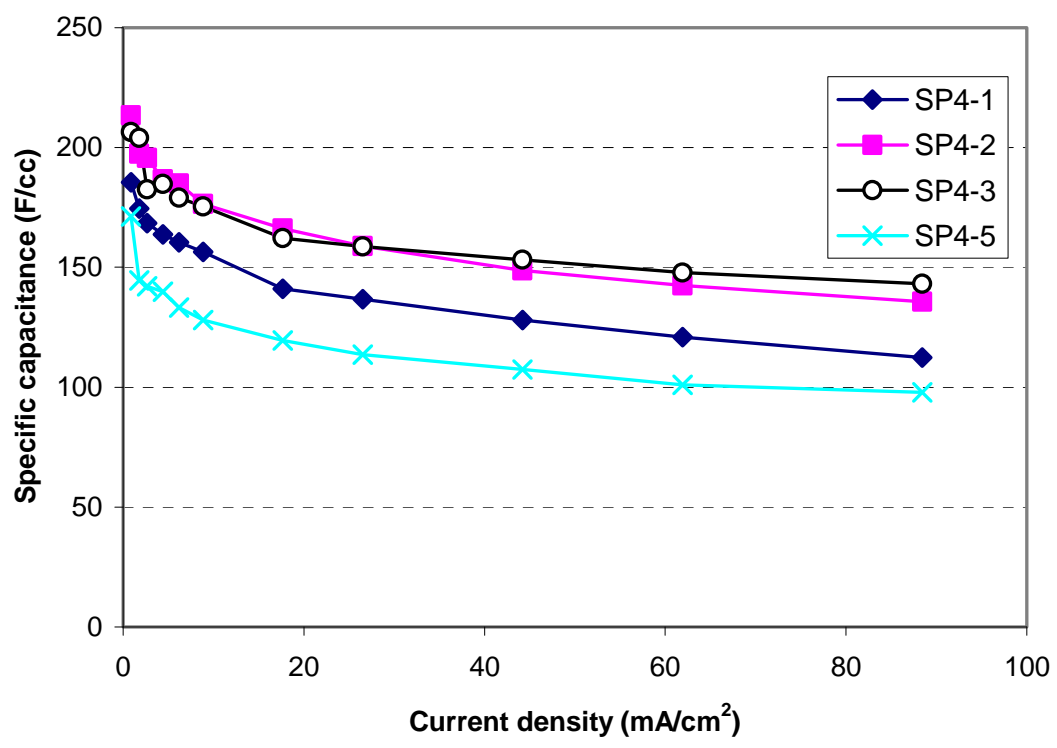

Figure 4.- Variation of the capacitance with current density: a) gravimetric capacitance; b) volumetric capacitance 


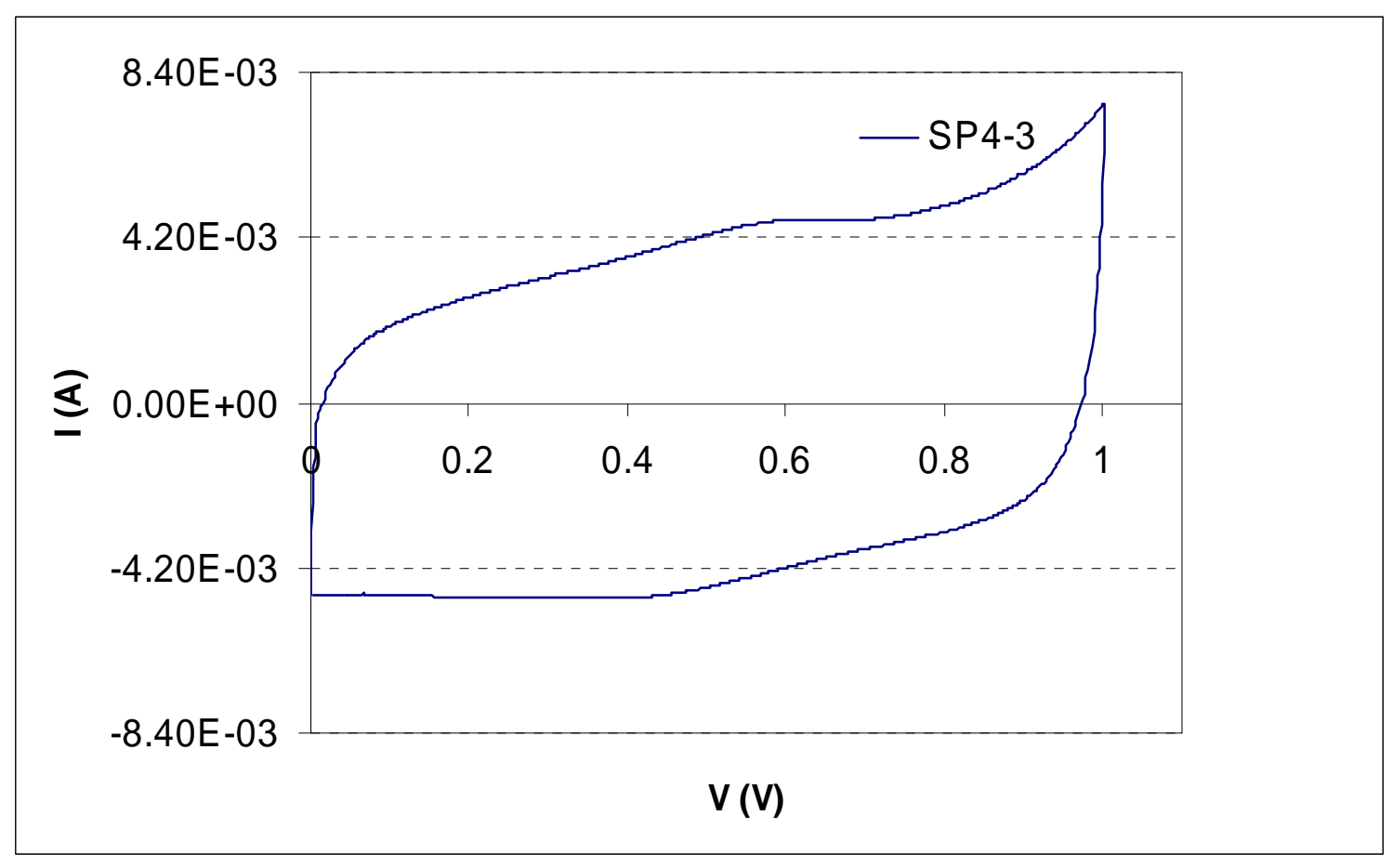

Figure 5.- Voltagram of sample SP4-3 obtained at $1 \mathrm{mV} / \mathrm{s}$. 